Ces altérations des laits peuvent être, en un certain sens, atténuées par l'addition correspondante de phosphates de calcium à l'état convenable.

Pour les laits acides, le phosphate à ajouter doit être riche en chaux, tandis qu'il doit être pauvre en chaux pourles laits paresseux.

Les fromages fabriqués à partir des laits traités s'affinent dans de très bonnes conditions. Leur maturation lente se produit sans l'apparition de goûts amers ou "putrides ". Ces fromages présentent à la coupe un très bon aspect et sont d'une qualité supérieure à celle des fromages préparés à partir des laits dont les altérations n'ont pas été corrigées.

\title{
REMARQUES SUR UN APPAREIL POUR LE doSAGE DE LA MATIËRE GRASSE DANS LA CASÉINE PRÉsURE
}

\author{
par M. Mard FOUASSIER \\ Expert-Chimiste près les Tribunaux
}

Dans le numéro 141 (Janvier 1935) de la Revue Le Lait, j'ai lu avec intérêt la description d'un appareil, et celle d'une technique s'y adaptant, pour le dosage de la matière grasse dans la caséine présure, présentées par M. J. Delorme.

L'intérêt que j'ai pris à la lecture de cet article était d'autant plus vif que j'avais antérieurement publié dans cette même Revue (n० 83, mars 1929, p. 269) un article analogue, dans lequel je présentais également un appareil pour l'application d'un même principe d'analyse.

Ce principe et ses modalités ne sont pas une nouveauté : je n'envisagerai donc pas l'attaque chlorhydrique de la substance sur laquelle il repose, mais seulement l'appareil proposé par M. DELoRME, appareil qui se différencie du tube très simple que j'avais indiqué, par l'apport d'un robinet qui supprime le pipettage et permet une décantation de la couche de solvant éthéré.

Je m'abstiendrai de toute critique concernant le dit appareil, qui peut avoir ses avantages dans certains cas industriels, malgré l'imprécision des pesées, mais je rappellerai que dans la méthode que j'ai décrite, - et qui est journellement employée, - j'utilise des tubes gradués, spécialement construits sur mes indications, dans lesquels on effectue l'attaque de la caséine au bain-marie en atmosphère acide, c'est-à-dire que toute diffusion de vapeurs chlorhydriques est évitée par l'adjonction d'un tube de dégagement muni d'une boule et dont la pointe effilée plonge dans de l'eau ; la légère surpression ainsi provoquée n'est pas sans activer l'attaque. Je n'ai pas eu à constater des variations dans les résultats en mainte- 
nant le chauffage au delà de l'attaque complète ; le temps de celle-ci est évidemment variable, mais il est bon de faire, pour ce facteur, une large part à la nature de la caséine mise en ceuvre.

Mon procédé permet le travail en série, ce qui n'est pas négligeable ; l'attaque au bain-marie (une demi-heure environ) peut être prolongée sans surveillance spéciale et sans porter préjudice à la sécurité ou à la rapidité de la méthode.

Le solvant éthéré étant ajouté dans le tube au liquide acide d'attaque, - comme je le fais moi-même, - M. Delorme recommande, après l'agitation qui convient, de laisser son appareil au repos pendant près de deux heures pour permettre la séparation des couches. Or, dans ce laps de temps, mon analyse peut être complètement effectuée, grâce à la centrifugation que j'ai préconisée, et sur laquelle j'attire l'attention pour la seconde fois.

La séparation spontanée des couches est rarement franche, et c'est pour obvier à cette cause d'erreur que mes tubes peuvent s'adapter dans une centrifugeuse Gerber. La centrifugation permet d'obtenir très rapidement la séparation nette des couches et la lecture facile du volume occupé par la couche éthérée, dont on prélève une partie aliquote, exactement mesurée avee une pipette, - ce qui ne présente aucune difficulté, - pour évaporation et pesée dans un vase à extrait préalablement taré.

Je n'insiste pas sur la simplicité des calculs à effectuer ensuite.

Ma méthode s'applique aussi bien à la caséine présure qu'à la caséine lactique. En ce qui concerne la caséine présure, j'utilise maintenant comme solvant l'éther seul, tandis que j'ai conservé pour la caséine lactique le mélange éther, éther de pétrole et alcool indiqué dans l'exposé que je viens de rappeler.

\section{BIBLIOGRAPHIE ANALYTIQUE}

\section{LES LIVRES}

\section{Martinet (J.). - Précis de chimie d'après les théories moder-} nes. Un volume relié de 934 pages. Gaston Doin et Cie éd., à Paris, 8, place de l'Odéon; 1934. 52 francs.

Parmi tous les traités de chimie, il convient de réserver une place particulière au "Précis de Chimie " de J. Martinet, docteur ès sciences physiques, écrit à l'usage des étudiants des facultés des sciences et de pharmacie. Il sera consulté avec profit par tous ceux qui, sans être vraiment des ehimistes, ont besoin d'acquérir ou de développer des connaissances en vue d'interprétation de phénomènes ou d'application pratique de cette science particulière.

Dans la première partie sont exposées les lois fondamentales de la ehimie, la structure des atomes, l'architecture moléeulaire, la réaction ehimique et, enfin, l'importante question des mélanges. 